\title{
SALÁRIO-HORA 2006
}
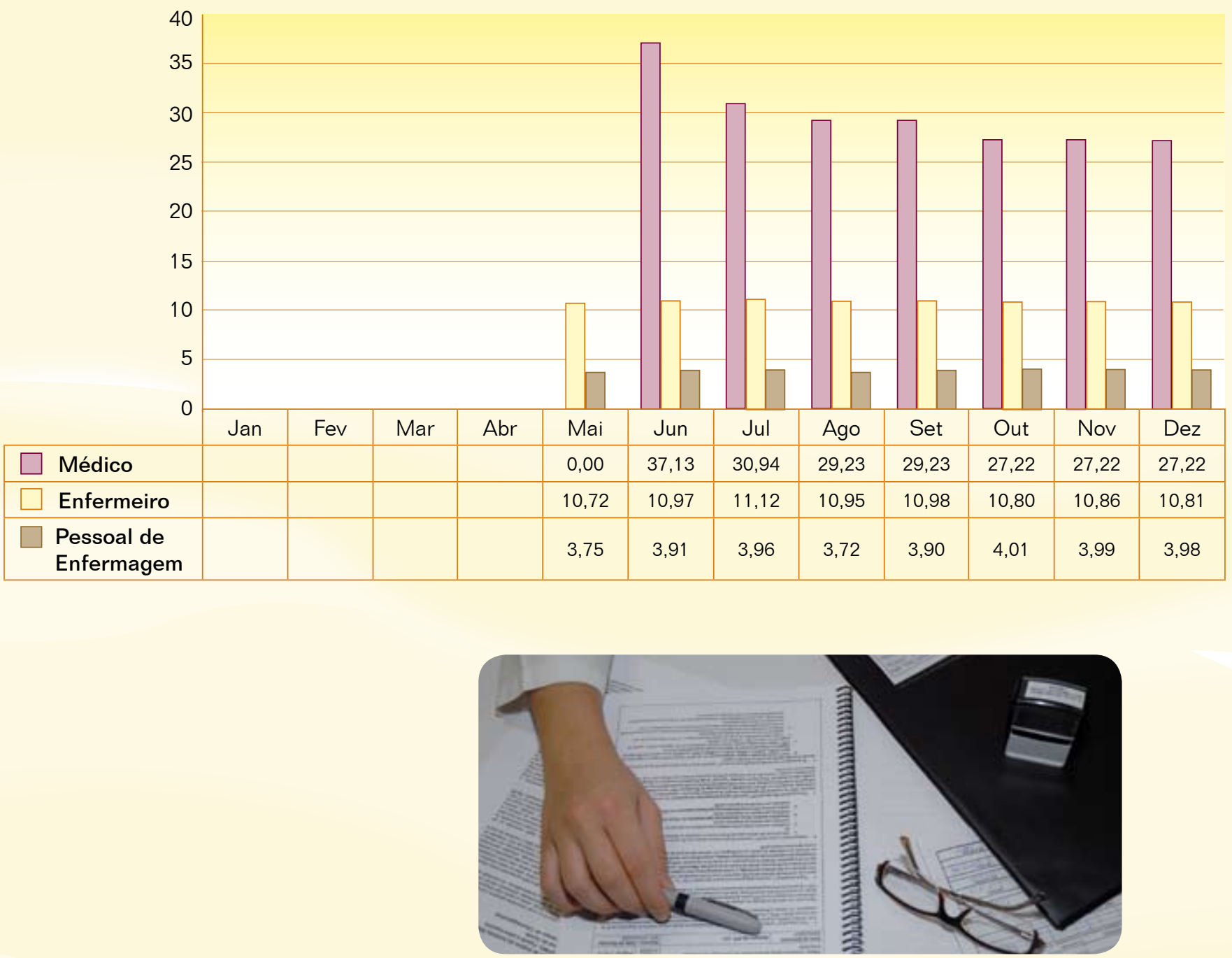

\section{SALÁRIO-HORA 2007}

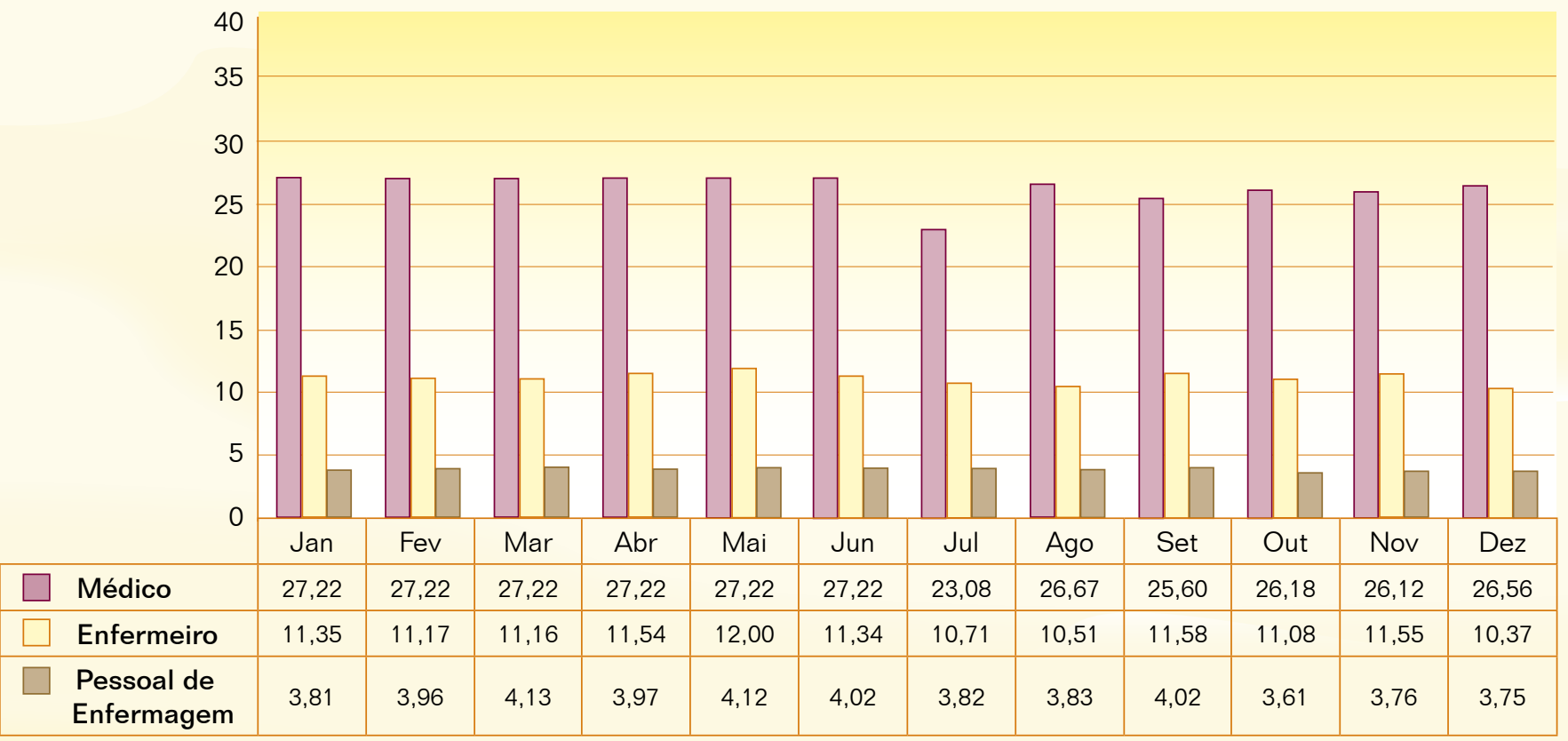




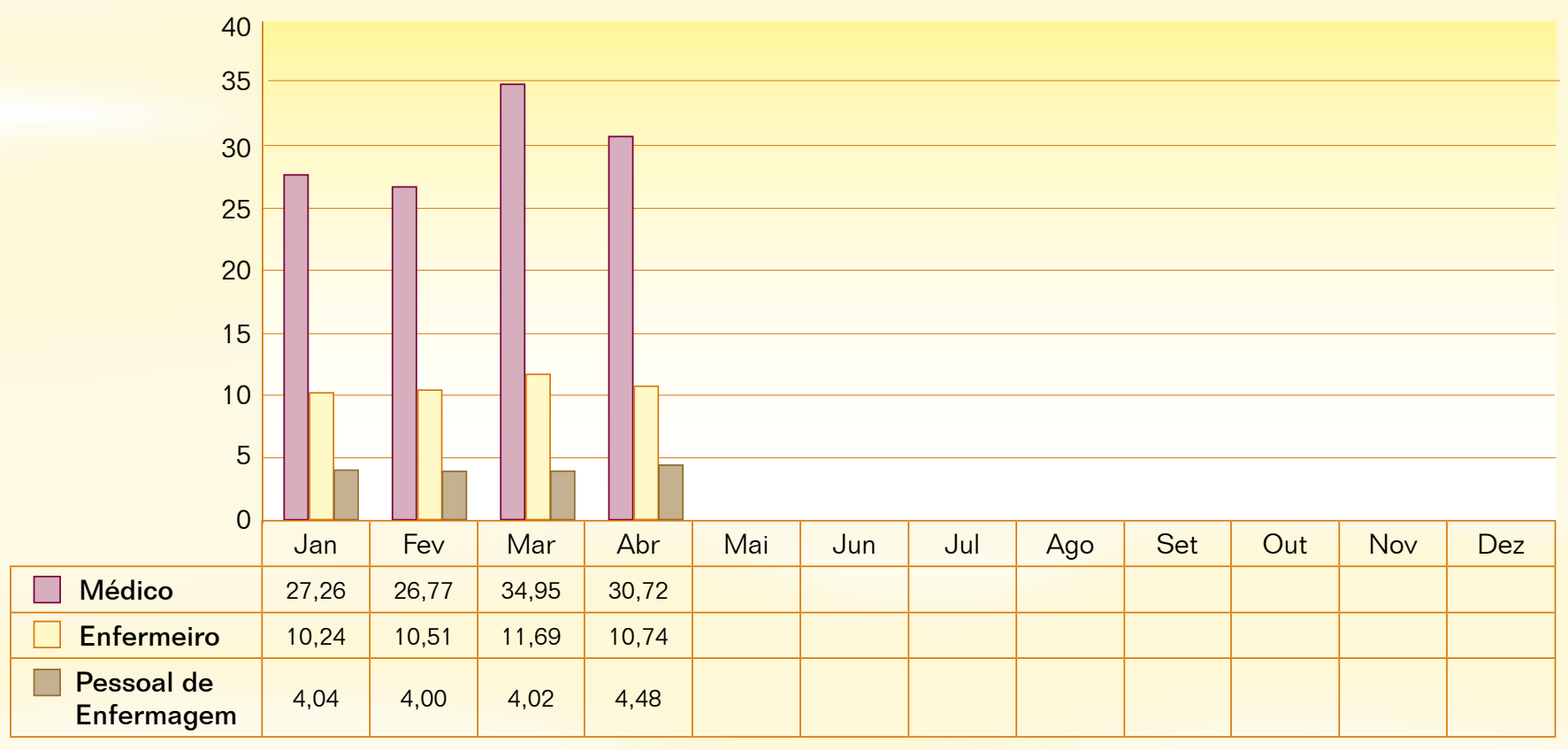

\section{SALÁRIO-HORA}

\section{Definição:}

Mediana dos salários-hora das seguintes profissões:
a) Enfermeiros
b) Pessoal de Enfermagem
c) Médicos Contratados

\section{Variáveis:}

- Total gasto em salários com enfermeiros: soma do salário base de todos os enfermeiros com formação universitária, registrados no COREN, contratados em regime CLT, não incluindo qualquer tipo de encargo, adicional ou benefício; ou,

- Total gasto em salários com pessoal de enfermagem: soma do salário base de todos os técnicos, auxiliares de enfermagem e atendentes autorizados pelo COREN, contratados em regime CLT, não incluindo qualquer tipo de encargo, adicional ou benefício; ou,

- Total gasto em salários com médicos contratados: soma do salário base de todos os médicos contratados em regime CLT, que atuam na área assistencial, não incluindo qualquer tipo de encargo, adicional ou benefício.
- Total de horas disponíveis do profissional: valor resultante do somatório das horas brutas, de acordo com a jornada contratual do profissional.

\section{Fórmula:}

\section{Total gasto em salários}

Total de horas disponíveis

Unidade: R\$̣/hora

Observação: O Indicador foi calculado para o período de maio de 2006 - data de início projeto - até abril de 2008 - data de fechamento da edição desta Revista. 


\section{COMPARAÇÃO DA VARIAÇÃO SALARIAL COM O IPCA E O INPC}

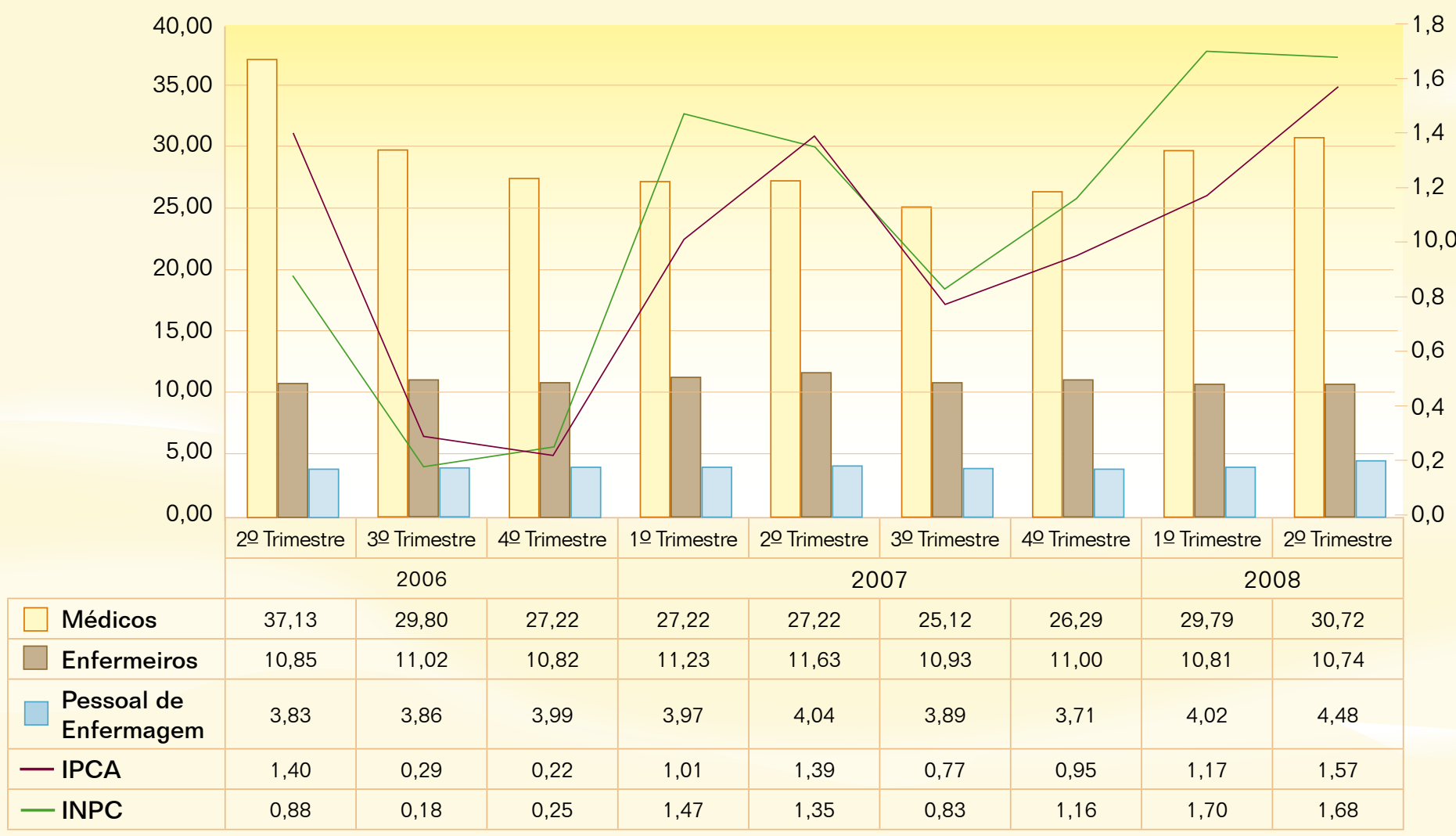

\section{COMPARATIVO DA VARIAC̣ÃO SALARIAL COM O IPCA E O INPC}

\section{Definição:}

Comparação entre a mediana do salário-hora trimestral dos funcionários representados e a média do Índice de Preços ao Consumidor Amplo (IPCA) e o Índice Nacional de Preço ao Consumidor (INPC). IPCA e INPC são calculados pelo IBGE: www.ibge.gov.br

\section{Variáveis:}

-Enfermeiros com formação universitária, registrados no COREN;

- Técnicos, auxiliares de enfermagem e atendentes, autorizados pelo COREN;

- Médicos que atuam na área assistencial.

Formula geral:

(Total de gastos em salários / Total de horas disponíveis)/3

Unidade: R\$̣/Hora

Observações: Os salários por hora são referentes aos trimestres mencionados. O indicador foi calculado para o período de maio de 2006 - data de início projeto - até abril de 2008 - data de fechamento da edição desta Revista.

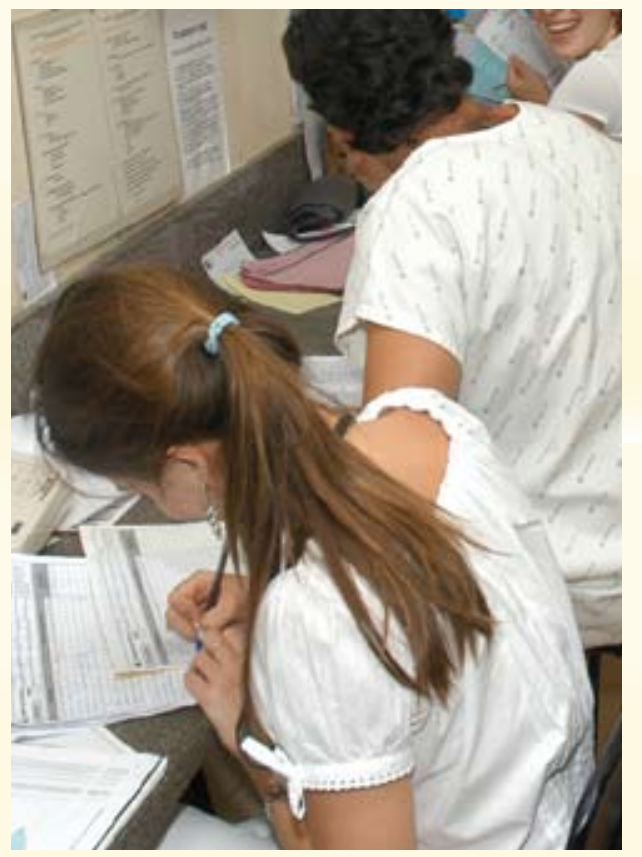



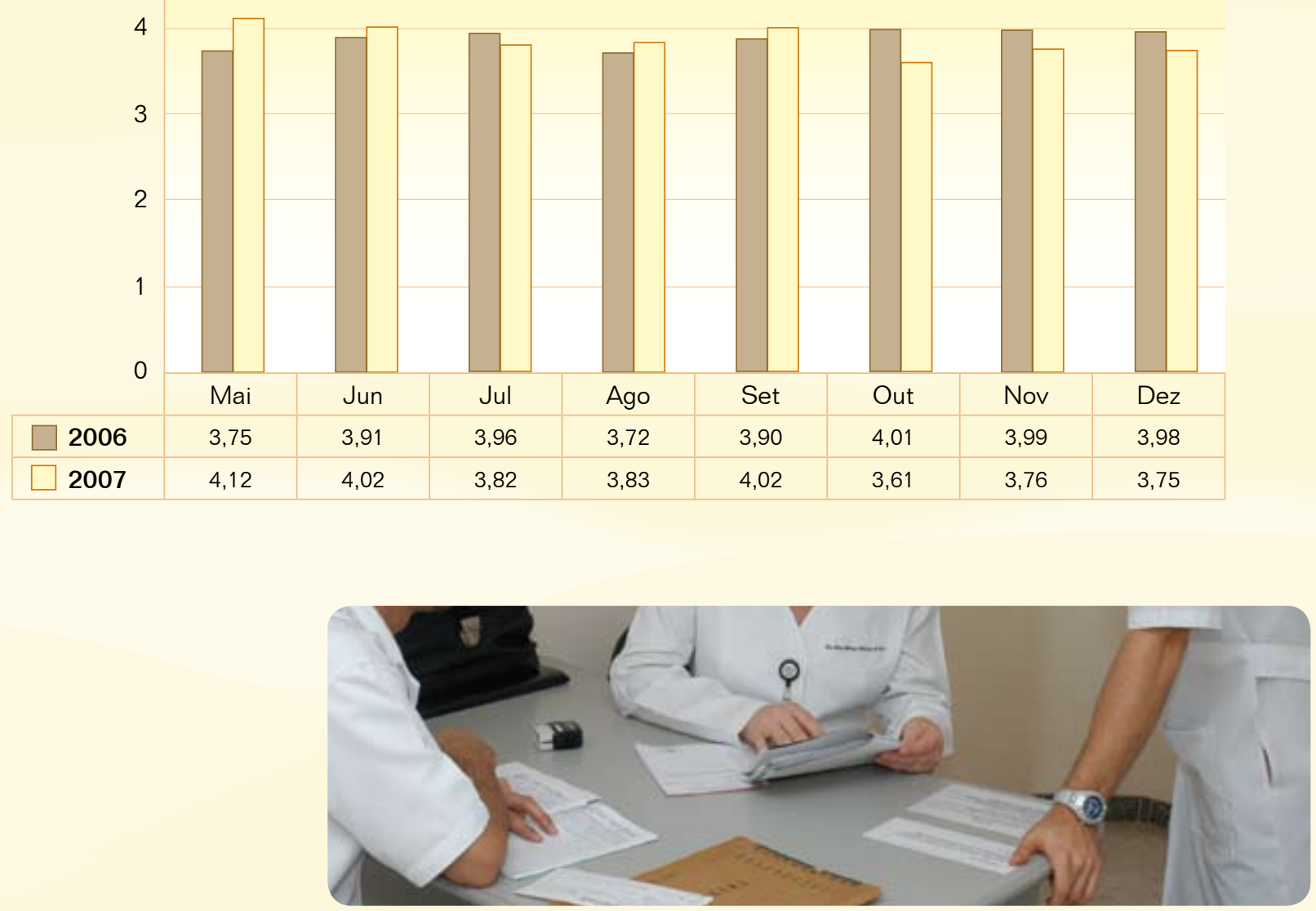

COMPARAC̣ÃO DA VARIAC̣ÃO SALARIAL - ENFERMEIRO

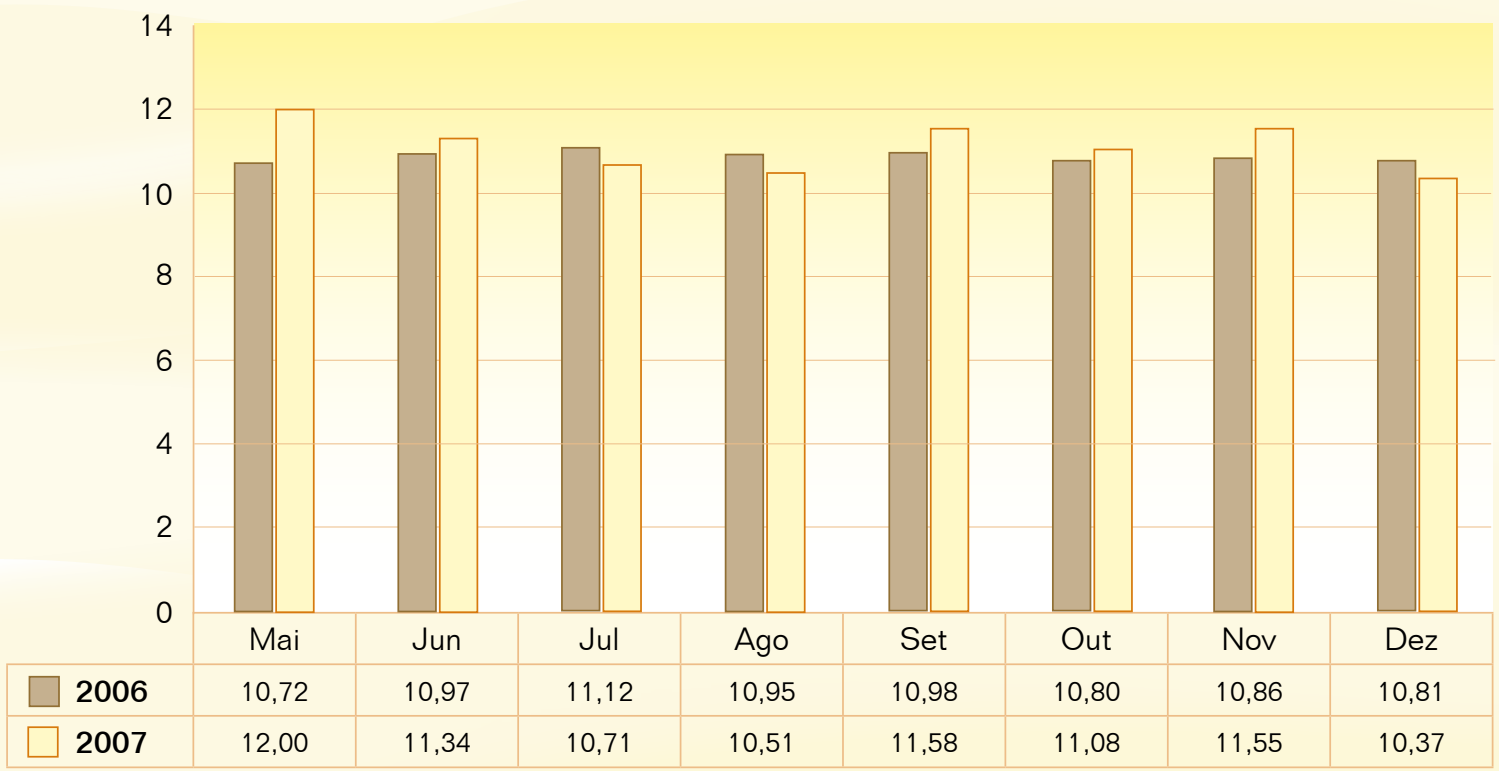


COMPARAÇÃO DA VARIAC̣ÃO SALARIAL - MÉDICO

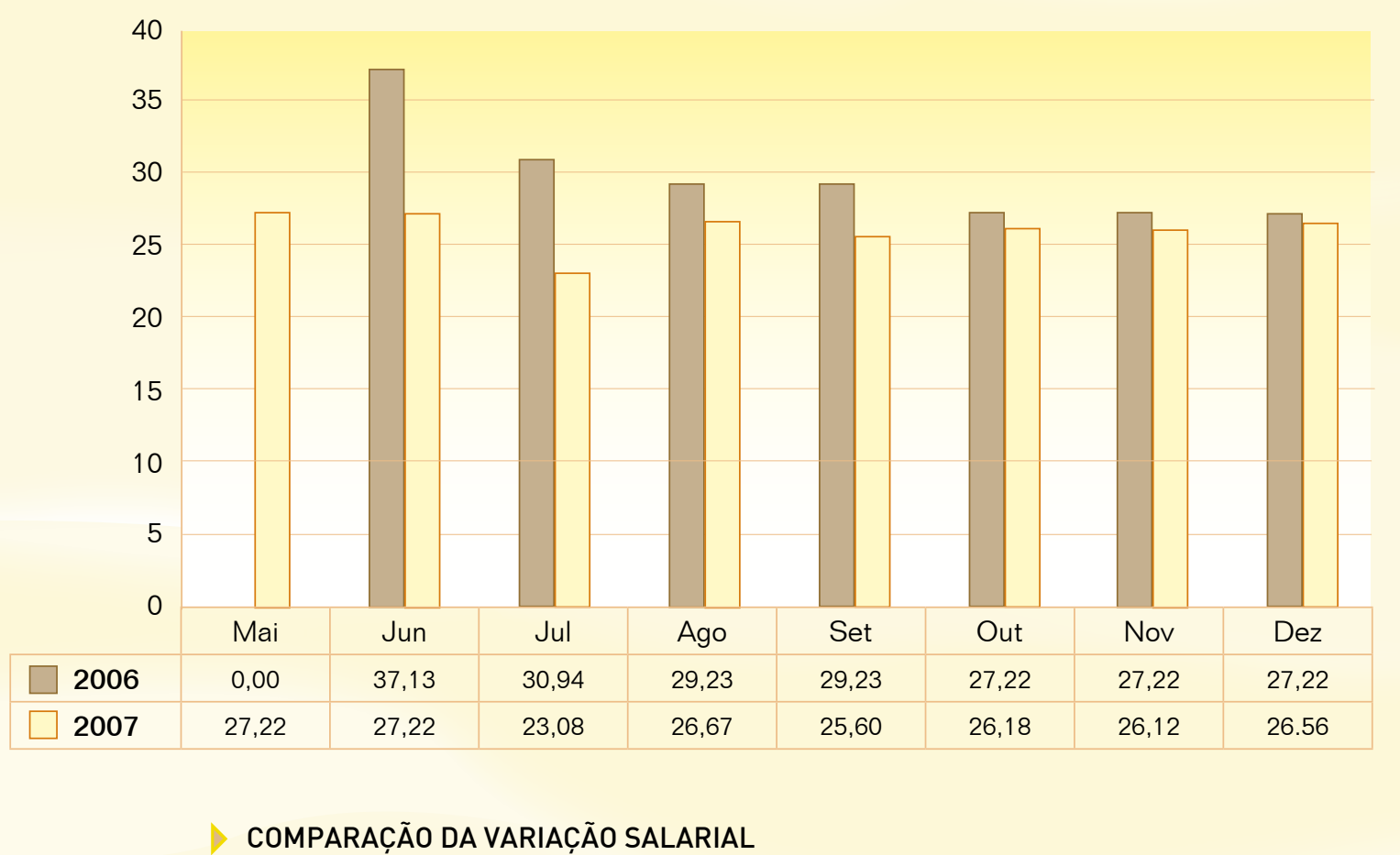

\section{Definição:}

Valores de salário-hora do profissional mês-a-mês.

\section{Variáveis:}

- Enfermeiros: enfermeiros com formação universitária, registrados no COREN.

- Pessoal de enfermagem: Técnicos, auxiliares de enfermagem e atendentes, autorizados pelo COREN.

- Médicos: médicos que atuam na área assistencial

Fórmula:

$$
\frac{\text { Total de gastos de salários }}{\text { Total de horas disponíveis }}
$$

Unidade: $\mathrm{R} \$ /$ Hora

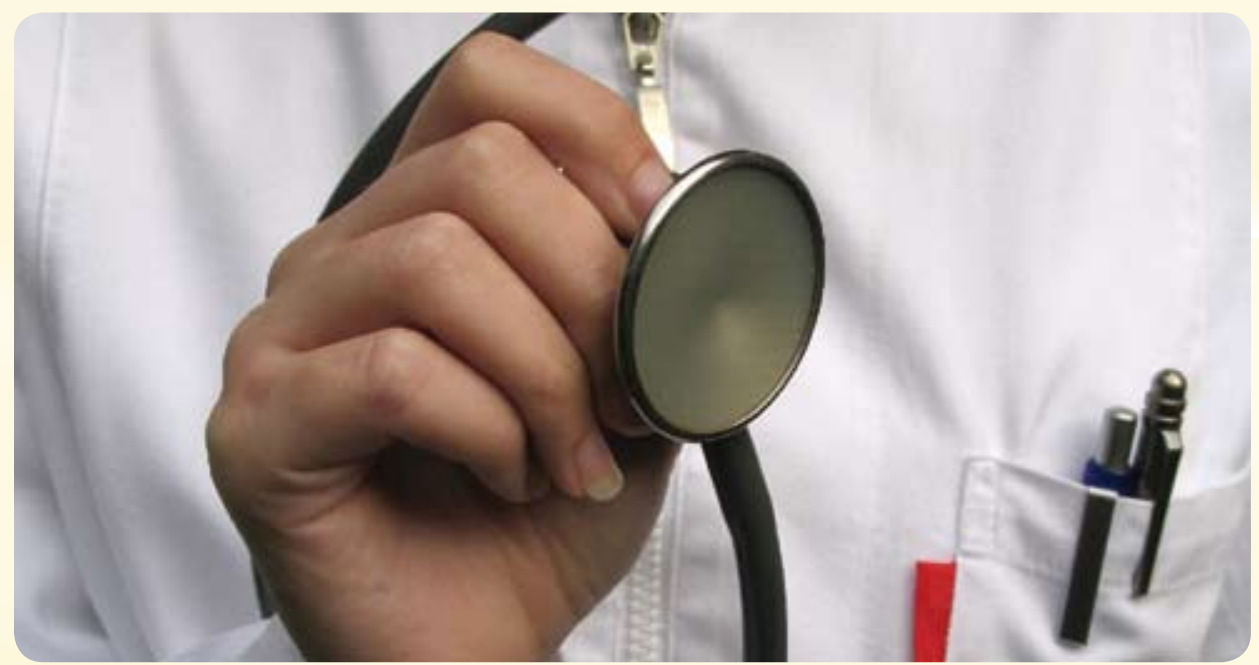




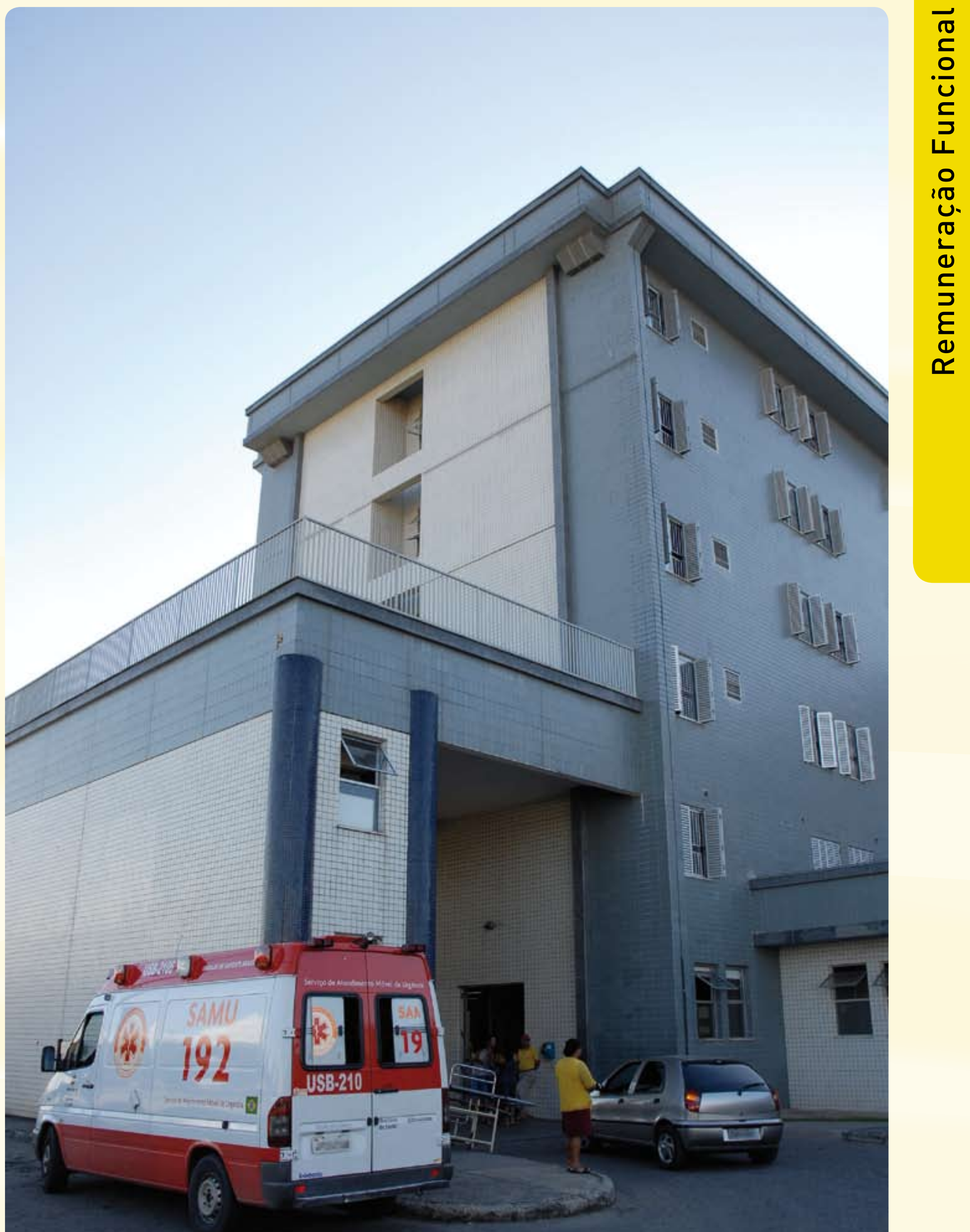

